\title{
Estimation of the Properties Porous STRUCTURES BY EXPERIMENT AND MODELING
}

\section{MARCIAN, P.; MAJER, Z.; REHOREK, L.; FloRIAN, Z. \& DLOUHY, I.}

Abstract: Highly porous brittle materials form a unique group with a large ratio of surface to the volume of the material. The application of these materials is once applications where light, and, at the same time, strong, structures are needed. The paper is focused on two main problems. The first part describes the results of a tensile test development on highly porous materials known as very complicated to perform. The second part of the paper is dedicated to the modelling of the porous structure using finite element calculations. The image processing principle of micro computer tomography device data is described. In order to easily create finite element method models the software was developed. A complete algorithm of finite element model formation is also included. Commercially available ceramic foam $85 \% \mathrm{Al}_{2} \mathrm{O}_{3}-14 \% \mathrm{SiO}_{2}-1 \% \mathrm{MgO}$ was used experiment part of the paper.

Key words: cellular structures, tensile test, MicroCT, image processing, FEM
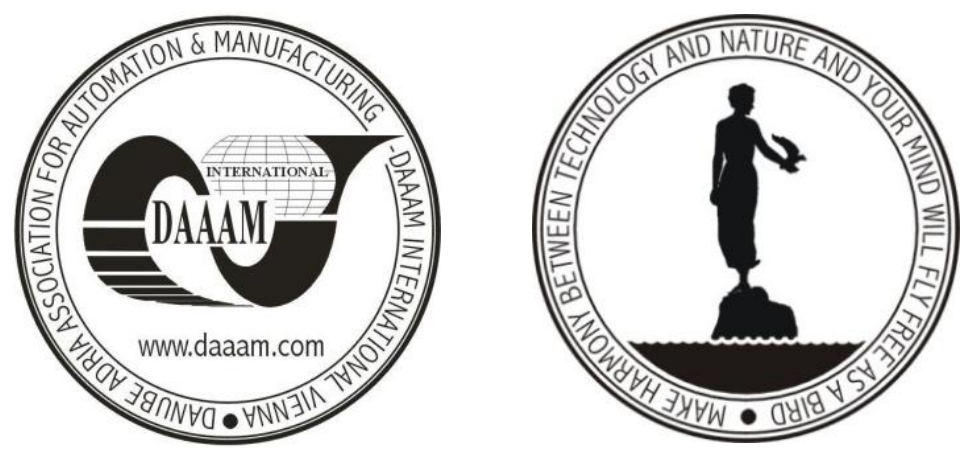

Authors' data: Ing. Marcian, P[etr]*; Ing. Ph.D. Majer, Z[denek]*; Ing. Rehorek, L[ukas]**; Ing. CSc. Florian, Z[denek]*; prof. Ing. CSc. Dlouhy, I[vo]***, * Brno University of Technology, Faculty of Mechanical Engineering, Technicka 2896/2, 61669 Brno, Czech Republic, ** Institute of Physics of Materials of the Academy of Sciences of the Czech Republic, Zizkova 22, 61662 Brno, Czech Republic, marcianp@seznam.cz, majer@fme.vutbr.cz, rehorek@ipm.cz, florian@fme.vutbr.cz, idlouhy@ipm.cz

This Publication has to be referred as: Marcian, P[etr]; Majer, Z[denek]; Rehorek, L[ukas]; Florian, Z[denek] \& Dlouhy, I[vo] (2011). Estimation of the Properties Porous Structures by Experiment and Modeling, Chapter 47 in DAAAM International Scientific Book 2011, pp. 573-584, B. Katalinic (Ed.), Published by DAAAM International, ISBN 978-3-901509-84-1, ISSN 1726-9687, Vienna, Austria DOI: $10.2507 /$ daaam.scibook.2011.47 
Marcian, P.; Majer, Z.; Rehorek, L.; Florian, Z. \& Dlouhy, I.: Estimation of the Pro...

\section{Introduction}

Nowadays, highly porous brittle materials encounter a wide range of usage in engineering practice, which is continuously increasing (Dawson et. Al., 2006), (Garrido et al., 2008). The interest in porous ceramic materials is connected above all with their unique properties, such as low relative weight, large specific surface area and high thermal insulation properties. In recent years, certain fields of the mechanical engineering industry have been replacing solid materials with light porous materials, which is especially due to the favourable hardness, strength and weight ratio (Brezny \& Green, 1990).

These materials are used in various types of catalytic converters, in light but strong structures used in aviation, and in the space industry. We should not forget the use of porous materials in tissue engineering, e.g. in bone tissue replacement (Boccaccini et al., 2005), etc. The structural similarity of spongy bone with porous materials predetermines these materials as bone fillings. Spongy bone tissue is porous and consists of small beams and bars, whose arrangement corresponds with the current state of loading. The architecture is structured in order to be the most solid. Appropriately adapted foam ceramics are, in contrast to commonly used inert ceramics, bioactive - the materials support integration between the bone and the implant. They enable attachment to or even intergrowth of bone cells; in many cases these porous structures transform into bone tissue (Boccaccini et al., 2005), (Hutmacher, 1990), (Miao et al., 2007).

In all mentioned fields, it is essential perfectly to understand the response of the porous material to mechanical loading, and in particular to know their exact mechanical characteristics important for applications. So far, mechanical tests included mostly compression and bend testing (Brezny \& Green, 1990). Tensile testing was neglected, mainly due to its complexity. In order to understand the behaviour of porous materials thoroughly it is necessary to know their performance under various types of loading.

The tensile test of brittle, highly porous materials is rather complicated (Rehorek et al., 2009), (Dlouhy et al., 2009). The most difficult problem is the attachment of a sample itself, its alignment with the loading axis and deformation characteristics measurement. The test specimen is usually destroyed during the testing. Therefore it is necessary to use contactless deformation measuring. Several possibilities may be applied for these purposes, such as digital image correlation or laser interferometry. Despite the difficulties with performing the tensile tests, the data offers very important information about the mechanical properties.

Owing to these experiments we can generate data, needed for calculations with the Finite Element Method (FEM). As mentioned above, experiments are very complicated, not only from the point of view of the realisation itself, also the economical point of view as well (price of the experimental material etc.). This is one of driving forces to create calculation models respecting porous structure and modelling the material performance in included applications. Micro Computer Tomography (MicroCT) have been used, allowing the 3D monitoring of the micro structure of objects in a non-destructive way enable the examination of objects 
smaller than one tenth of a millimetre (Moon et al., 2009), (Giesen et al., 2009) or even less.

Image processing methods make it possible to reconstruct a particular object from pictures obtained using selected imaging methods. 3D visualisation can be carried out in two ways. The first one is a projection of the so-called "voxel" object, from which a $3 \mathrm{D}$ image of the scanned object can be created. The second possibility is to export the object in such a way that enables processing in CAD/CAM applications and FEM systems. There are available professional commercial programs such as Mimics, 3D-Doctor, Vascops etc., which do not always meet the requirements when solving a specific problem. Moreover, they also require rather sophisticated knowledge by the user. A significant drawback of these programs is the speed of downloading of the processed object into the STL format and their inability to process larger objects. For the reasons mentioned above it is useful to create alternatives to these commercial programmes.

The aim of the paper can be seen in development of experiment and computational quantification of ceramic foam material response to mechanical loading.

\section{Experiment}

\subsection{Material properties}

For the purposes of the experiment, the commercially available ceramic foam Vukopor ${ }^{\circledR}$ A (Lanik, Czech Republic), with a chemical composition of (wt \%) $85 \% \mathrm{Al}_{2} \mathrm{O}_{3}-14 \% \mathrm{SiO}_{2}-1 \% \mathrm{MgO}$ was used as the investigated material.

Two groups of samples were investigated, having the porosity, 10 and 60 pores per linear inch (PPI). The filling was $24 \%$ for 10 PPI and $22 \%$ for 60 PPI, respectively the relative density for this material is 0.16 for 10 PPI and 0.15 for 60 PPI. Figure 1 shows pictures of structures taken with the Scanning Electron Microscope (SEM).

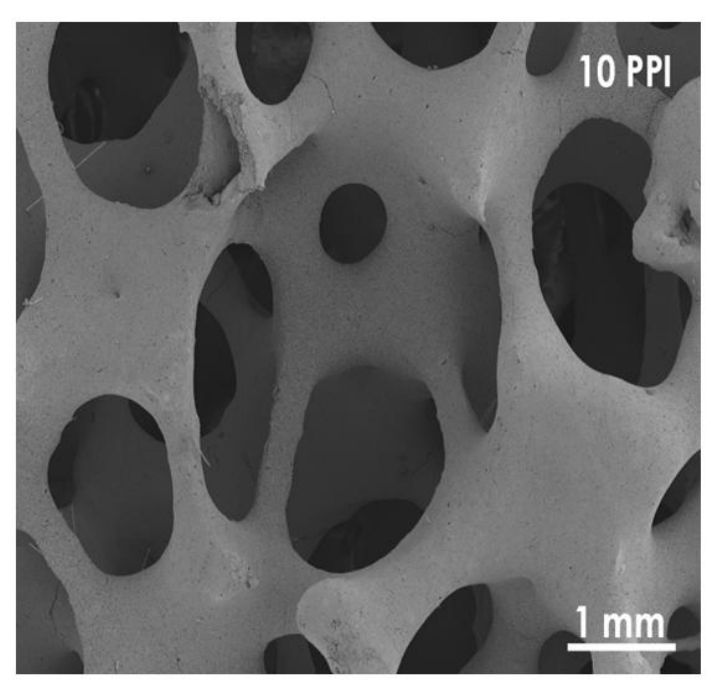

a)

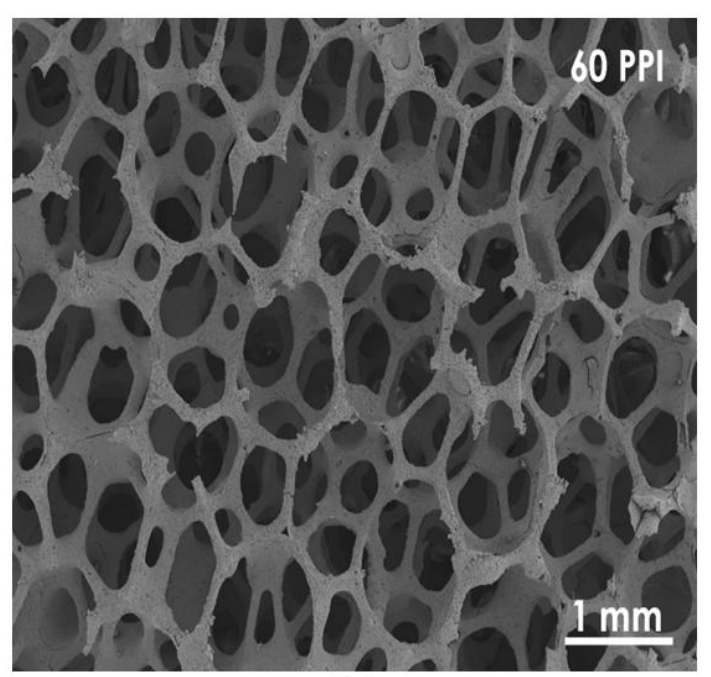

b)

Fig. 1. The cellular structure of Vukopor® A for 10 PPI (a) and 60 PPI (b) 
Marcian, P.; Majer, Z.; Rehorek, L.; Florian, Z. \& Dlouhy, I.: Estimation of the Pro...

\subsection{Mechanical tests}

Tensile tests were conducted on the Zwick/Roell Z050 electromechanical testing machine. To realize the needed tensile test, a methodology of tensile testing for brittle ceramic foams was developed. It included the development of a special device to fix the sample without damaging it. Alignment with tensile force was ensured by the loose fitting of clamping jaws from one side on the spherical surface and the second side was fixed with a Cardan shaft.

During the test the deformation of the sample was measured as well. Because of brittle crusting of these materials during any contact, the method of digital image correlation using the Correli Q4 programme was chosen. Images were recorded with a Canon EOS 40D digital SLR.

\subsection{Results of tensile tests}

Based on the tensile tests and the measuring of the fracture surface area using image analysis, the tensile strength values of both samples types were determined. The results are summarized in Figure 2.

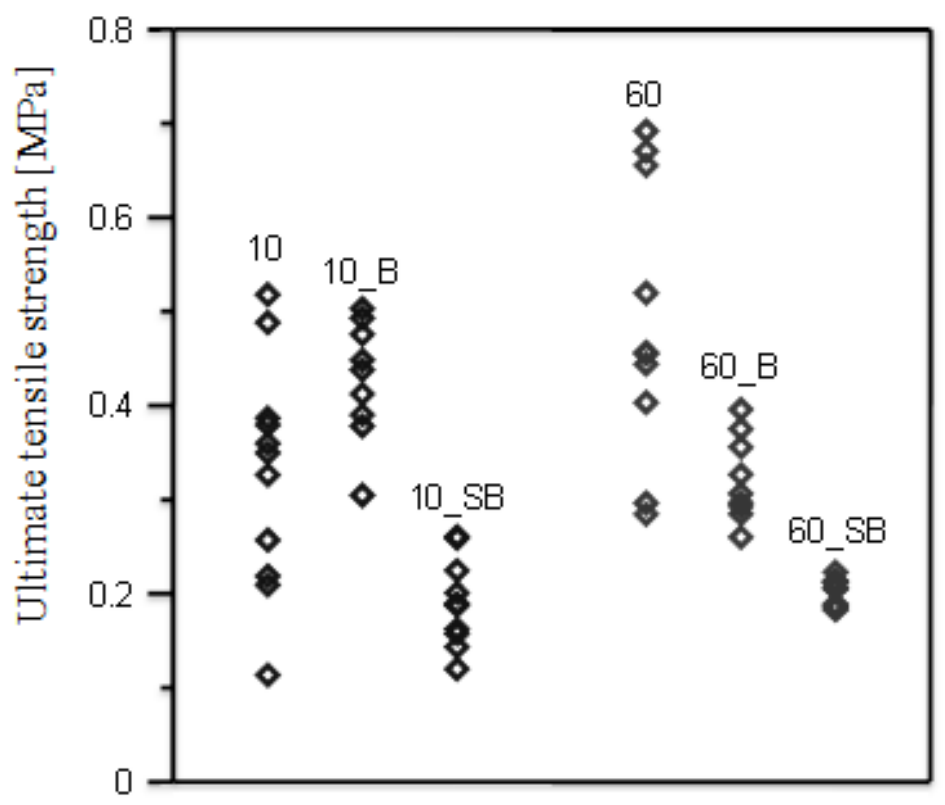

Type of porosity sample type

Fig. 2. Tensile strength of samples with 10 PPI and 60 PPI for 10x10x30 $\mathrm{mm}^{3}(-)$, $15 \times 15 \times 40 \mathrm{~mm}^{3}(\mathrm{~B})$ and $30 \times 30 \times 90 \mathrm{~mm}^{3}(\mathrm{SB})$

There are several phenomena in the Figure 2. First of all, the tensile strength depends substantially on the size of pores - PPI. The impact of the sample size is also noticeable, where increasing sample size causes higher statistical probability of a considerable defect in the structure and consequently decreases the tensile strength values.

The strength decrease due to sample size is more noticeable in samples with a finer pore structure. With the increasing sample size the scatter of measured data decreases due to the higher density of small beams in the cross-section, which results in a more homogeneous distribution of tension in the sample. This behaviour is 
especially noticeable in samples with 60PPI, where the density of small beams is higher. In samples with 10 PPI it can be expected that in order significantly to decrease the scatter of the tensile strength values, bigger samples than the measured ones would be needed.

This fact is caused by an insufficient number of cells in the cross-section. As the size cell in this type is $2.2 \mathrm{~mm}$ on average, there are not enough cells in the crosssection to transmit load and the measured data of tensile strength is distorted because of difficulties in defining the loaded cross-section. In samples of such a small size with a large cell dimension, the so-called defect zone plays a significant role. This zone is composed of peripheral cells of the foam structure which are not adequately joined and which do not contribute to the strength of the ceramic foam structure.

In small samples the defect zone gains a remarkable importance. The thickness of this zone approaches the size of cells of a particular foam material. If this model is applied to the sample cross-section, an effective cross-section reduced by the defect zone can be obtained. In this way we can determine corrected effective fracture strength for the foam materials. The corrected data of tensile strength for Vukopor®A samples are described in Figure 3.

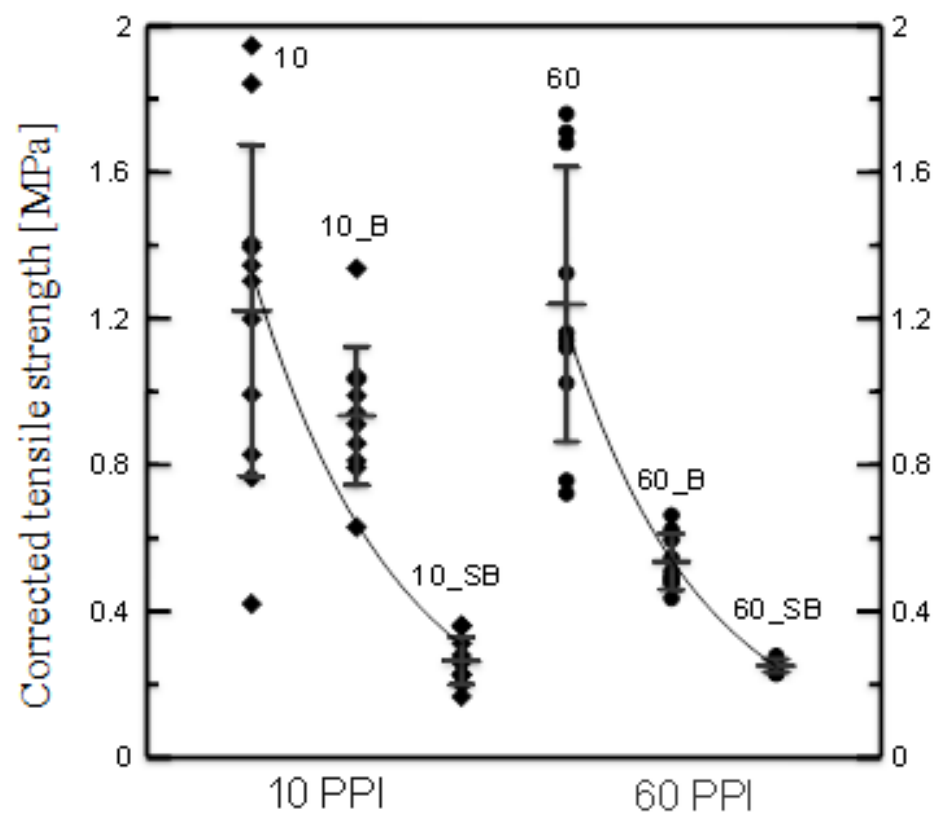

Fig. 3. Corrected tensile strength data for both ceramic foam cell size values

The graph of the corrected tensile strength data indicates that, after the defect zones are taken into consideration, the results of tensile strength are rather increased and the differences in figures between 10 and 60 PPI samples are negligible. In samples with 10 PPI size the effect of samples size is more noticeable. This behaviour was shielded in non-corrected data by the influence of the defect zone.

\section{FEM Model}

The study of porous and spongy materials, such as bone tissue, is in focus interests in many disciplines including biomechanics. For solving problems in 
Marcian, P.; Majer, Z.; Rehorek, L.; Florian, Z. \& Dlouhy, I.: Estimation of the Pro...

biomechanics computing modelling is very often used (Borak et al., 2010), (Fuis et al., 2008), whereas it is very difficult and expensive to perform live experiments. In creation of the computational models it is necessary to have enough input information about the design of objects. The most commonly used input data to create computational models are data obtained from 3D imaging methods (CT - Computed Tomography, MRI - Magnetic Resonance Imaging and micro-CT device).

\subsection{MicroCT device}

Micro-CT devices (contrary to conventional medical devices such as CT and MRI) allow the monitoring of the complex architecture and structure of the material. $\mathrm{CT} / \mathrm{MRI}$ and micro-CT generate images from which various information needed for subsequent development of models at different levels can be extracted. Each method has advantages but also disadvantages and the choice of a particular imaging device depends on the target use of the data (Krsek et al., 2007).

Micro-CT provides the same information as conventional CT (from a physical point of view) because they are working on the same principle of absorption of X-ray beams passing through the object being detected. Compared with conventional CT, micro-CT allows monitoring of the microstructure of the scanned object (Giesen et al., 2009). This is due to much a higher resolution of micro-CT (typically 5 to $20 \mu \mathrm{m}$, while CT $0.5 \mathrm{~mm}$ ). It is not so essential for practical treatment, but it has significant influence for research into the microstructure of bone and highly porous materials. Comparison of Standard CT and micro-CT scan with the actual bone cut is shown in Figure 4 (cut lower jaw). From the micro-CT and standard CT can be the material characteristics of being scanned object determined using the calibration relations from the individual pixels (Fritsch et al., 2011), (Rho et al., 1995), (Valasek et al., 2010).

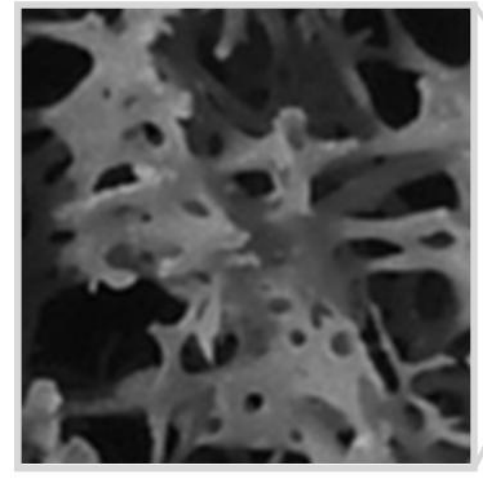

a)

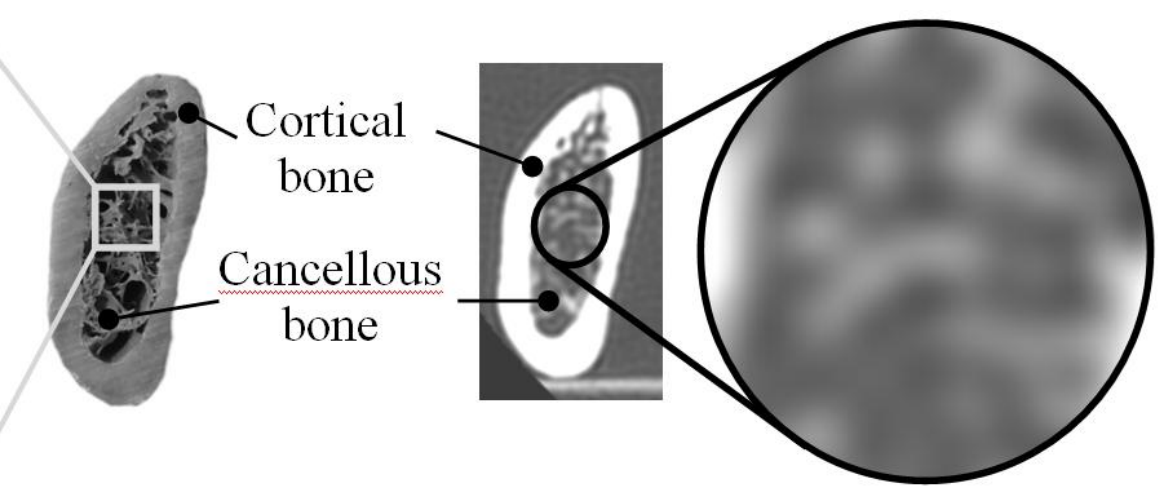

b)

Fig. 4. The example of micro-CT (a) and standard CT (b) images

During obtaining of the micro-CT of hard materials it can give rise to the socalled artefacts (defects). In Figure 5 the original image from the micro-CT (a) and the image with changed contrast (b) are shown. In this picture there are clearly visible shadows - artefacts. In most cases there are two types of artefacts: (i) circular (c-top) and (ii) surface resulting from the interaction of X-rays with the surface of the object 


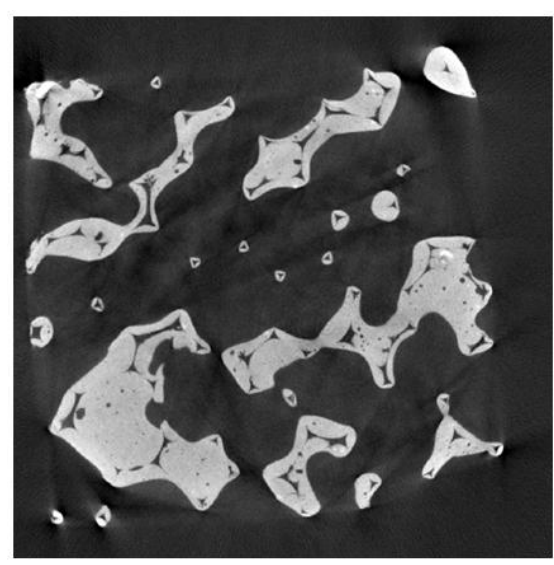

a)

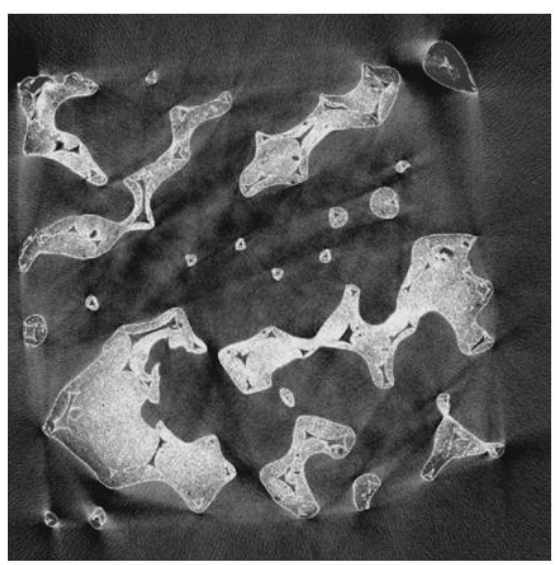

b)

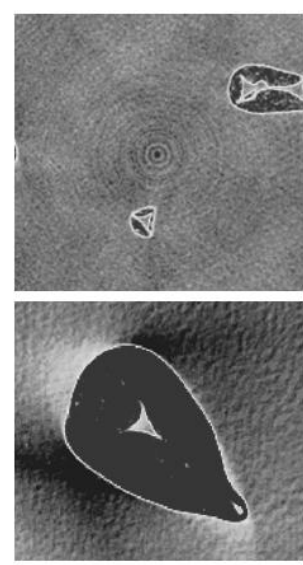

c)

Fig. 5. Example of artefacts: the original image (a), the changed contrast (b), circular (c-top) and surface artefacts (c-bottom)

(c-bottom). The number of artefacts can be directly affected by the setting of the micro-CT alone.

\subsection{Creation of microCT model using STL Model Creator software}

For faster image processing and analysing of the micro-CT data the software called STL model Creator was developed in Matlab 2009b (Konecny et al., 2010). For effective work the program is equipped with the graphical user interface (GUI). This allows the user quick and intuitive control.

The program loads images in various formats (which are currently available). Micro-CT images are usually in TIF format or stored in a RAW file, which contains all the images at once. It is for this reason to avoid significant data loss (colour depth) through re-saving in another format such as JPEG. The whole series usually contains several hundred images, usually around one thousand. The input data represents a discrete description. The program can create a 3D model from the data in vectored form. First, it is necessary to do the most important part of the process model segmentation. It is an operation in which the data with common properties is selected (Bankman, 2009), (Bruna \& Sehr, 1990). This provides a new image - a binary image, see Figure 6, where the white colour determines the selected object and its boundaries.

Generally, three basic types of segmentation are known:

The first one is automatic segmentation, which is used for huge scan series. For automatic segmentation in STL Model Creator software the threshold function is used. This important function selects pixels in a definite range on the basis of their intensity. The pixels with the highest intensity correspond to the studied object (white colour in Figure 6 on the right). On the other side the pixels with the lowest intensity correspond to pores. Disadvantage of this method is that it doesn't detect artefacts in scans.

The second type is manual segmentation. This method enables the user to take full control over segmentation and the final model. The user can segment and select the proper area by themselves. For this purpose the program's tools e.g. crosshair or selected polygon, are necessary, by which it is possible to select the area manually. 
Marcian, P.; Majer, Z.; Rehorek, L.; Florian, Z. \& Dlouhy, I.: Estimation of the Pro...

The main disadvantage of this method is significant time demands. In addition, the user has to have some experience and knowledge of object shape (they determine its boundary themselves).

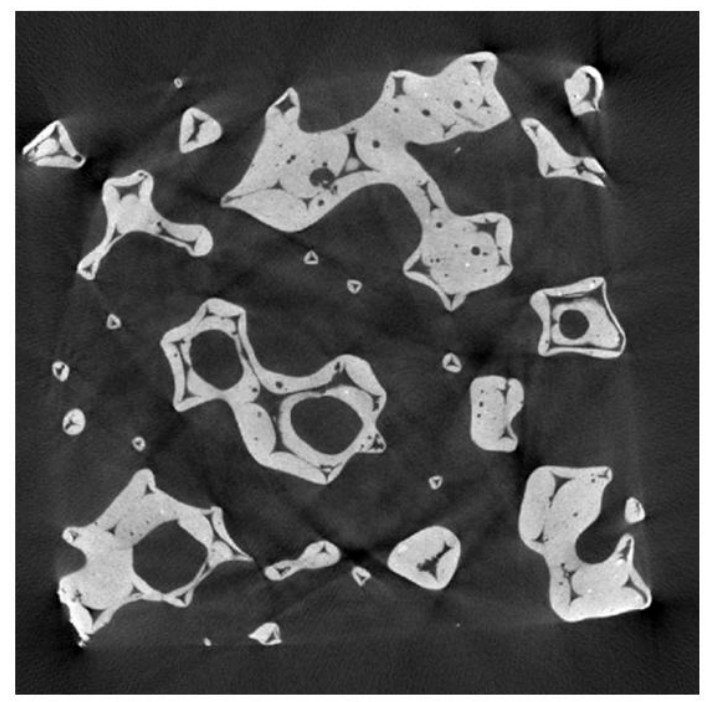

a)

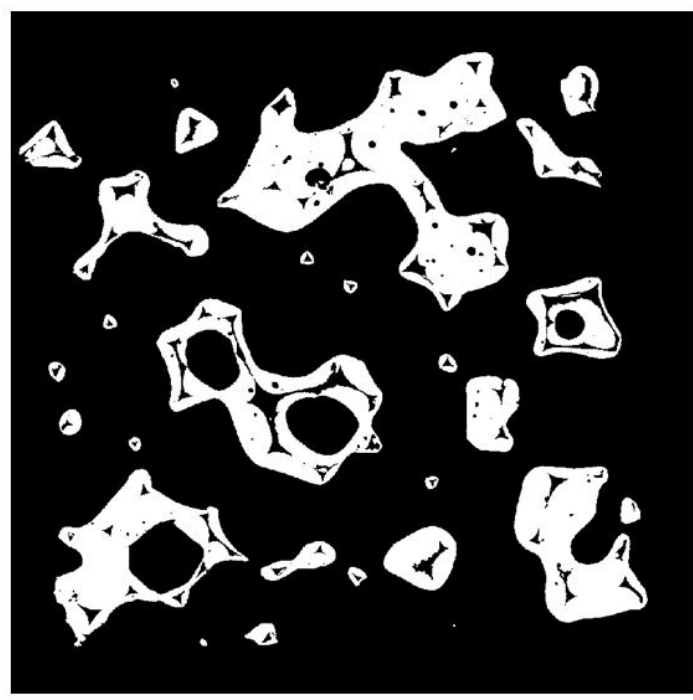

b)

Fig. 6. Original picture (a) and picture created by automatic segmentation (b)

Both previously mentioned methods together are called hybrid segmentation. It connects the advantages of both methods and enables the fast creation of a quality model. Performing hybrid segmentation using the STL Model Creator software is done very simply and effectively.

It is necessary to note that for segmentation it is possible to use any kind of commonly available software, e.g. Image J, CorelDraw, Adobe etc. Each contains advanced filters for segmentation and program tools for manual segmentation. But it is necessary to have some knowledge of this software.

It is important to set the voxel size before creating the $3 \mathrm{D}$ object, respectively setting the pixel size and voxel higher. These data in an informative file is available with microCT scans. It assigns the third dimension to every section after entering three voxel dimensions. By this we mean the distances between sections are arranged. After this operation the user is able to get section in additional in sagittal- and coronary-planes, see Figure 7. It is necessary to calculate the missing pixels for real image resolution using interpolation, and the real image can be shown by this.

For further processing in CAD/CAM applications or FEM systems it is important to export the data. For this purpose the STL polygonal net format is used. This file is supported by most other software - it is a standard supported format which is also executable in freeware software. STL files only describe the surface geometry of a three-dimensional object without any representation of colour, texture or other common CAD model attributes. The STL can be saved in two ways: in ASCII code or binary. ASCII code listing is very simple, but the result is a big file, which can create many problems when we open it in professional CAD software (CATIA, SolidWorks, Rhinoceros, etc.). On the other hand, saving it in binary form leads to a smaller size of the saved file and professional programs do not have any 
problems in opening it. The listing is more complicated. In STL Model Creator the saving is solved by using ASCII code.

\section{Transversal-sections}
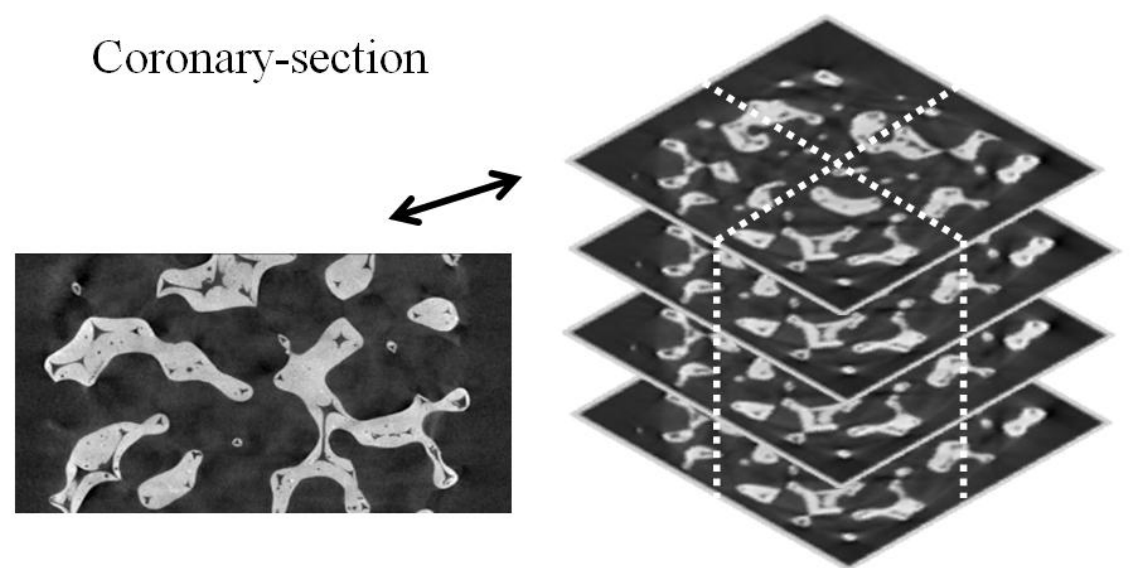

Sagittal-section

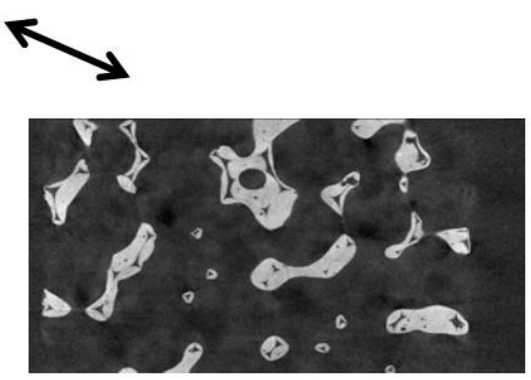

Fig. 7. Various section projections of micro-CT data

\subsection{Model for FEM computation}

The ANSYS 12.0 software (Ansys Inc., Canonsburg, PA, USA) was used for creating the FEM model. High porous structures have extreme requirements for computational model creation. These structures were discretized using SOLID 187 tetrahedrons. Since the high porous structures are very complicated in shape, it is important to pay attention to the creation of mesh, see Figure 8. A sensitive analysis was performed for choosing the optimal elements size and nodes number too. The mesh creation time mainly depends on the size and object complication.

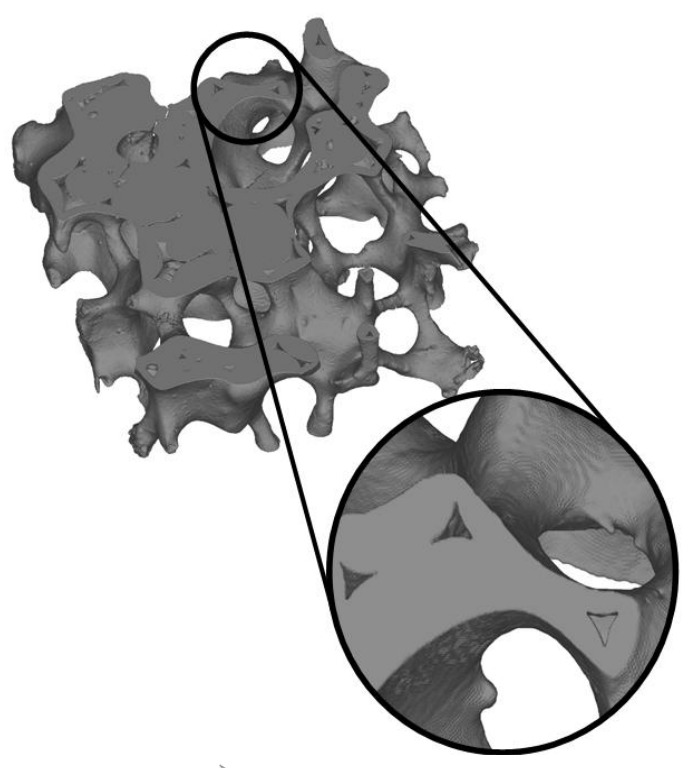

a)

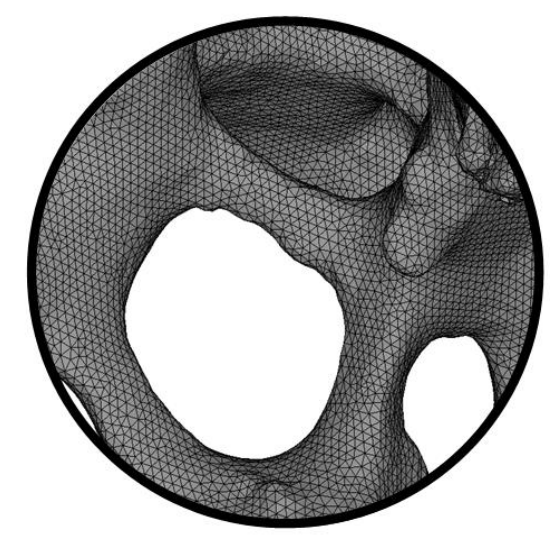

b)

Fig. 8. FEM model of ceramic foam geometry (a) and illustration of mesh (b)

For example, 4.8 million elements and 6.7 million nodes were used, see Figure 8. Generally, the model was created and solved on an eight core PC with 12 GB memory and 1TB HD. After creation of the mesh the material properties had to be 
Marcian, P.; Majer, Z.; Rehorek, L.; Florian, Z. \& Dlouhy, I.: Estimation of the Pro...

included. The structure had homogenous properties from the microstructure point of view. The used material was described by two elastic constant $E(70000 \mathrm{MPa})$ a $v$ $(0.22)$.

The values of Young's modulus and Poisson ratio were determined experimentally by using nanoindentation. The indentation loading curve was measured on a Zwick/Roell ZHV20/Z2.5 instrumented micro indenter. The micro indenter is equipped with a $200 \mathrm{~N}$ load cell for estimation indentation force. The Vickers diamond indenter was used. The Young's modulus of ceramic foam Vukopor ${ }^{\circledR}$ A. was determined from dependence of force on indentation depth.
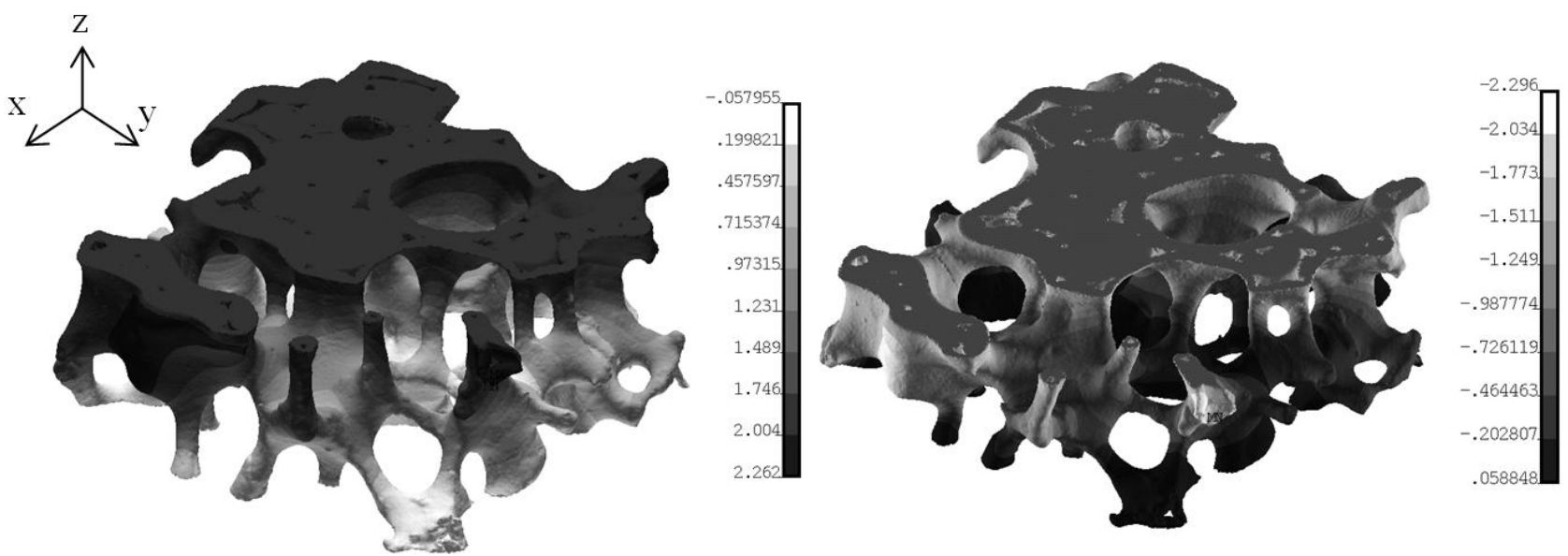

Fig. 9. Z-displacement [mm] of sample under compression and tensile
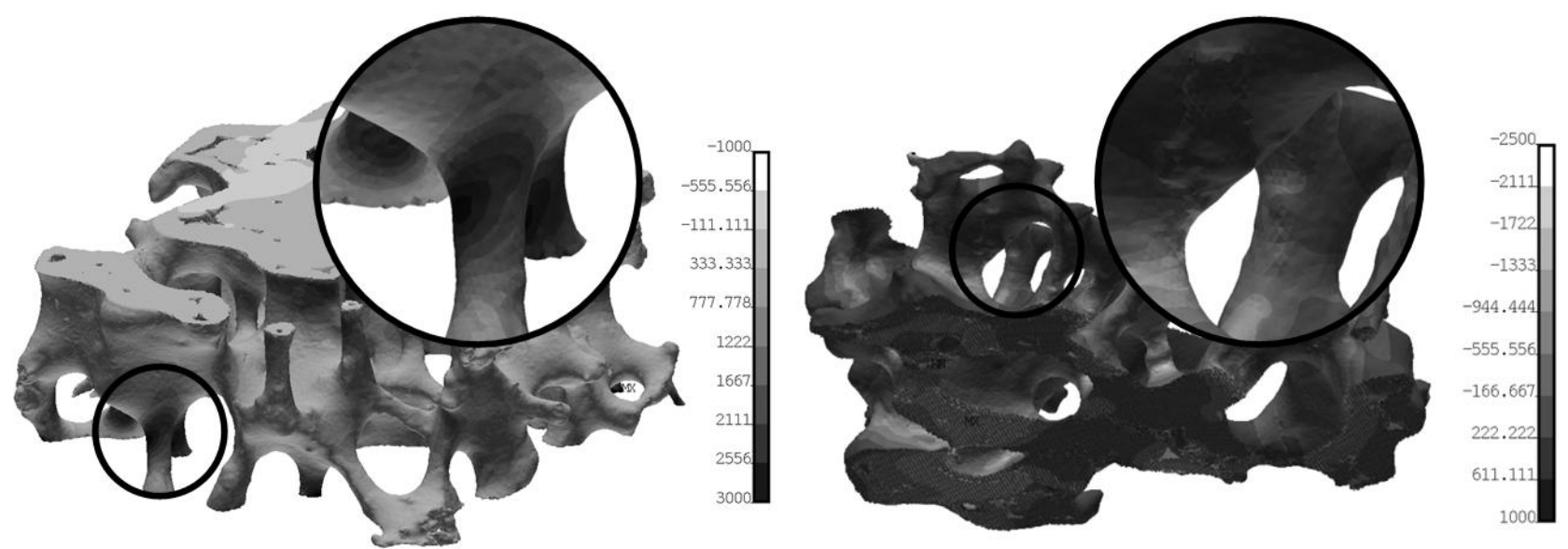

Fig. 10. Normal stress [MPa] (Z-direction)

The specimen was loaded onto the $\mathrm{Z}$-axis by means of pre-defined displacements of all nodes at one side of the specimen in the XY-plane. The specimen was fixed on the opposite side. The specimen was loaded in tension as well as in compression so the proportional elongation of the specimen was $1 \%$. The showing of ceramic sample analysis is shown in Figure 9 and Figure 10. The z-displacements reach almost the same value in the tensile and pressure loading of sample. The stress analysis is difficult because there are a lot of singularities in sharp mesh transitions. The real stress values can be read only from areas without stress singularities. For this reason the scale is modified for black and white range in Figure 10 so the stress level lines would be shown on the struts. 


\section{Conclusion}

This paper has been focused brittle foam materials response to mechanical loading. There is very high interest in these materials due to their unique properties. The low relative mass, the huge surface and high thermal insulation abilities predetermine these materials for very broad use in engineering practice.

The tensile testing methodology of highly porous materials was developed. This methodology was verified using ceramic foam samples commercially produced as ceramic filters Vukopor ${ }^{\circledR}$.

Dependence of tensile strength on sample size and pores size effects was found. The tensile stress values decrease by increasing the sample's dimension and so the measured values scatter decreases. These properties are dependent on cell size, from which ceramic foam was created. The difference between samples strength with 10 and 60 PPI (pores value) was not observed.

The computational model at the micro level with respect to pores (respective strut structure) was suggested. The FEM modelling has big potential mainly in biomechanics, where the interaction of ceramic bone replacement with lived bone tissue, fixators or implants is studied. The FEM model creation has significant influence in this area and opens possibilities for the future, e.g. for the development of bone reparation.

\section{Acknowledgements}

This work was supported by grant specific research FSI-J-11-3/942 and FSI-S11-12/1225 and project of Czech Science Foundation Nr. 101/09/1821.

\section{References}

Bankman, H. I. (2009). Handbook of Medical Image Processing and Analsysis, Elsevier, ISBN 978-0-12-373904-9, Johns Hopkins University, Baltimore, MD, USA

Boccaccini, A. R., Blaker, J. J., Maquet, V., Day, R. M. \& Jerome, R. (2005). Preparation and characterisation of poly(lactide-co-glycolide) (PLGA) and PLGA/Bioglass ${ }^{\circledR}$ composite tubular foam scaffolds for tissue engineering applications, Materials Science and Engineering C, Vol. 25, No.1, 23-31, ISSN 0928-4931

Borak, L., Marcian, P., Florian, Z. \& Bartakova, S. (2010). Biomechanical Study of Disk Implants, Part I., Engineering Mechanics, Vol. 17, No. 1, 49-60, ISSN $1802-1484$

Brezny, R. \& Green, J. D. (1990). Characterization of edge effects in cellular materials. Journal of Materials Science, Vol. 25, No. 11, 4571-4578, ISSN 0022-2461

Brezny, R. \& Green, J. D. (1990). Mechanical behavior of cellular ceramics, Materials science and technology, Vol. 11, 463-516, ISSN 1743-2847 
Marcian, P.; Majer, Z.; Rehorek, L.; Florian, Z. \& Dlouhy, I.: Estimation of the Pro...

Bruna, J.; \& Sehr, A. (1989). Computed tomography of bones and joints, Univerzita Karlova, ISSN 0567-8250, Praha

Dawson, E. A., Barnes, P. A., Chinn \& M. J. (2006). Preparation and characterisation of carbon-coated ceramic foams for organic vapour adsorption. Carbon, Vol. 44, No. 7, 1189-1197, ISSN 0008-6223

Dlouhy, I; Rehorek, L. \& Chlup, Z. (2009). Tensile properties of Open Cell Ceramic Foams, Key Engineering Materials, Vol. 409, 168-175, ISSN 1013-9826

Fritsch, A., Dejaco, A., Komlev, V., Swieszkowski, W., Jaroszewicz, J., Bongaers, E. \& Hellmich, Ch. (2011). Translation of CT data into voxel - specific micromechanics - based elasticity tensors, Micro - CT User Meeting, 108-112, ISBN 978-90-81678- 100

Fuis, V., Hlavon, P. \& Janicek, P. (2008). Contact Surfaces of the Big Joints - Sites of the Developments of Limit States and Other Considerations, Engineering Mechanics, Vol. 15, 381-388, ISSN 1802-1484

Garrido, G. I., Patcas, F. C., Upper, G., Tuerk, M., Yılmaz, S. \& KraushaarCzarnezki, B. (2008). Supercritical Deposition of Pt on $\mathrm{SnO}_{2}$-Coated $\mathrm{Al}_{2} \mathrm{O}_{3}$ Foams: Phase Behaviour and Catalytic Performance. Applied Catalysis AGeneral, Vol. 338, No. 1-2, 58-65, ISSN 0926-860X

Giesen, E. B. W.; Ding, M.; Dalstra, M. \& van Eijden, T. M. G. J. (2004). Changed morphology and mechanical properties of cancellous bone in the mandibular condyles of edentate people. Journal Dental Research, Vol. 83, No. 3, 255259, ISSN 0022-0345

Hutmacher, D. W. (2000). Scaffolds in tissue engineering bone and cartilage. Biomaterials, Vol. 21, No. 24, 2529-2543, ISSN 0142-9612

Konecny, O., Marcian, P., Borak, L., Valasek, J., Krpalek D. \& Florian Z. (2010). STL Model Creator, http://biomechanika.fme.vutbr.cz, software

Krsek, P.; Krupa, P. \& Cernochova, P. (2007). Teeth and Jaw 3D Reconstruction in Stomatology. MEDIVIS '07 Proceedings of the International Conference on Medical Information Visualisation - BioMedical Visualisation.23-28, ISBN 07695-2904-6, Zurich

Miao, X., Tan, L. P., Tan, L. S. \& Huang, X. (2007). Porous calcium phosphate ceramics modified with PLGA-bioactive glass. Materials Science and Engineering C, Vol. 27, 274-279, No.2, ISSN 0928-4931

Moon, H. S., Won, Y. Y., Kim, K. D., Ruprecht, A., Kim, H. J., Kook, H. K. \& Chung, M. K. (2004). The three-dimensional microstructure of the trabecular bone in the mandible. Surgical and Radiologic Anatomy, Vol. 26, No. 6, 466473, ISSN 0930-1038

Rehorek, L., Dlouhy, I. \& Chlup, Z. (2009). Tensile Behaviour of Open Cell Ceramic Foams. Ceramics - Silikaty, Vol. 53, No. 4, 237-241, ISSN 0862-5468

Rho, J. Y., Hobatho, M. C. \& Ashman, R. B. (1995). Relations of mechanical properties to density and CT numbers in human bone. Medical Engineering \& Physics, Vol. 17, No. 5, 347-355, ISSN 1350-4533

Valasek, J.; Marcian, P., Krpalek, D., Borak, L., Florian, Z. \& Konecny, O. (2010). Material Properties of Bone Tissue Obtained from CT for Biomechanics Purposes. Mendel Journal series, Vol. 16, No.1, 483-490, ISSN: 1803- 3814 